\title{
COVID-19 HASTALIĞINDA ANTI-SITOKIN TEDAVILER: IL-6 RESEPTÖR INHIBITÖRÜ (TOSILIZUMAB) VE IL-1 RESEPTÖR ANTAGONISTI (ANAKINRA)
}

\author{
ANTI-CYTOKINE TREATMENTS IN COVID-19 DISEASE: IL-6 RECEPTOR INHIBITOR \\ (TOCILIZUMAB) AND IL-1 RECEPTOR ANTAGONIST (ANAKINRA)
}

\author{
Atalay DOĞRU1 \\ ${ }^{1}$ Süleyman Demirel Üniversitesi Tıp Fakültesi, İç Hastalıkları Anabilim Dalı, Romatoloji Bilim Dalı, Isparta-Türkiye
}

Cite this article as: Doğru A. Anti-cytokine Treatments in Covid-19 Disease: IL-6 Receptor Inhibitor (Tocilizumab) and IL-1 Receptor Antagonist (Anakinra). Med J SDU 2021; (ozelsayi-1):163-166.

Öz

Koronavirüs hastalığı 2019 (COVID-19) ilk kez AraIık 2019 tarihinde Çin'in Wuhan kentinde ortaya çıktı ve büyük bir küresel salgına neden oldu. Tüm dünyada halk sağlığı için önemli bir problem haline geldi. Hastalık geçirenlerin büyük çoğunluğu iyi bir prognoza sahip olmasına rağmen bazı hastalarda özellikle akciğeri etkileyen makrofaj aktivasyonu sendromuna (MAS) neden olmaktadır. Hastalığı geçiren bireylerde beklenen inflamasyon yanıtından hiperinflamasyona geçişte sitokin artış hızı ve sitokin miktarının rolü olduğu bilinmektedir. MAS gelişen hasta grubunda mortalite oranları yüksek seyretmektedir ve hastaların klinik ve laboratuvar bulgularında kısa sürede ortaya çıkan değişiklikler görülmektedir. Bu nedenle dinamik bir tedavi süreci ihtiyacı vardır. Özellikle solunum desteği ihtiyacı olan hastalarda glukokortikoid tedaviler önerilmektedir. Glukokortikoid yanıtı olmayan hastalarda anti-sitokin tedaviler gündeme gelmektedir. Anti-sitokin tedavilerden yararlanabilecek hasta grubunun doğru ve vaktinde tanımlanması, etkili ve güvenli bir tedavi planlanması açısından önem taşımaktadır.

Anahtar Kelimeler: Anakinra, Covid-19, Sitokin fırtınası, Tosilizumab,

\begin{abstract}
Coronavirus disease 2019 (COVID-19) first appeared in Wuhan, China in December 2019 and has caused a massive global pandemic. It has become an important problem for public health all over the world. Although the majority of those who suffer from the disease have a good prognosis, it causes macrophage activation syndrome (MAS) that affects the lung in some patients. It is known that the rate of cytokine increase and the amount of cytokines play a role in the transition from the expected inflammation response to hyperinflammation in individuals with the disease. Mortality rates are high in the patient group with MAS, and changes in the clinical and laboratory findings of the patient are observed in a short time. Therefore, a dynamic treatment process is needed. Glucocorticoid treatments are recommended, especially in patients who need respiratory support. Anti-cytokine treatments come into question in patients with no glucocorticoid response. It is important to identify the patient group who can benefit from anti-cytokine therapies correctly and on time, in order to plan an effective and safe treatment.
\end{abstract}

Keywords: Anakinra, Covid-19, Cytokine storm, Tocilizumab, 


\section{Giriş}

Şiddetli akut solunum sendromu korona virüsü 2 (SARS-CoV-2) ilk kez Aralık 2019 tarihinde Çin'in Wuhan kentinde ortaya çıktı ve kısa sürede tüm dünyayı etkiledi. Koronavirüs hastalığı 2019 (COVID-19) olan hastaların büyük çoğunluğu iyi bir prognoza sahip olmasına rağmen hastaların \% 10 kadarında hastalığın başlangıcından sonraki 8-14 gün içinde akciğer hasarı, akut solunum sıkıntısı sendromu (ARDS) ve birden fazla organ tutulumu görülmektedir. Solunum yetmezliği gelişen bu şiddetli vakalarda, hiyalin membran oluşumu, inflamatuar hücre infiltrasyonu ve mortaliteye yol açan yoğun bir sitokin salımı gibi bir dizi patolojik bulgu izlenmektedir. Sitokin fırtınası, ARDS' nin ve çoklu organ yetmezliğinin başlıca nedenlerinden biri olarak kabul edilir ve hastalığın şiddetlenmesi sürecinde önemli bir rol oynar $(1,2)$.

Hastalık üç faza bölünebilir: faz I (erken enfeksiyon), saptanabilir virüs içeren veya içermeyen asemptomatik evre; faz II (pulmoner), üst solunum yolu tutulumu olan şiddetli olmayan semptomatik faz; ve faz III (hiperinflamasyon), hipoksi ile ciddi, potansiyel olarak ölümcül bir hastalık, akciğerde 'buzlu cam' infiltrasyonları ve yüksek viral yük ile ARDS ye ilerleme. Hastalığın hiperinflamasyon fazına ilerlemesini virüs yükü ve yaş, cinsiyet, genetik yapı ve interferon yanıtı gibi konağa ait faktörler belirlemektedir (3). Hastalığı geçiren bireylerde beklenen inflamasyon yanıtından hiperinflamasyona geçişte sitokin artış hızı ve sitokin miktarının rolü olduğu bilinmektedir. Hastalarda ateşin devam etmesi, oksijen saturasyon düşüklüğü, ferritin yüksekliği, lenfopeni, d-dimer yüksekliği, interlökin 6 (IL-6) düzey yüksekliği, artış gösteren C-reaktif protein (CRP) değerleri ve karaciğer fonksiyon testlerinde (ALT, AST, LDH) yükseklik hiperinflamasyon fazına geçişi düşündürmektedir (4). Sitokin fırtınası ile karakterize makrofaj aktivasyonu sendromu (MAS) tedavisinde öncelikle glukokortikoid tedaviler önerilmektedir. Yeterli yanıt alınamadığında ise IL-6 reseptör inhibitörü, IL-1 reseptör antagonisti, Janus kinaz (JAK) enzimini inhibe eden ruksolitinib, barisitinib gibi tedaviler gündeme gelmektedir $(5,6)$. T.C Sağlık Bakanlığı Bilimsel Danışma Kurulu tarafından Kasım 2020 tarihinde yayınlanan anti-sitokin tedavi önerilerinde COVID-19 ilişkili MAS tablosu gelişen hastalarda glukokortikoid tedavilere yeterli yanıt alınamadığında biyolojik tedavi kullanılmasının mümkün olabileceği belirtilmektedir (7).

\section{IL-6 Reseptör İnhibitörü (Tosilizumab)}

Tosilizumab, IL-6 reseptörüne karşı geliştirilmiş rekombinant humanize monoklonal antikordur. IL-6 reseptörüne bağlanarak IL-6' nın bağlanmasına engel olur. Subkutan ve intravenöz kullanım yolu mevcuttur. İntravenöz kullanım için 80-200-400 mg halinde flakonları mevcuttur. Romatoloji pratiğinde $8 \mathrm{mg} / \mathrm{kg} / \mathrm{ay}$ dozunda, maksimum 800 mg olacak şekilde kullanılır. Subkutan formu ise 162 mg hazır enjektör şeklindedir ve haftalık olarak kullanılır $(8,9)$. Covid-19 bağlı hiperinflamasyonda intravenöz formu tercih edilmektedir. Emzirme ve hamilelik döneminde kullanılmamalıdır. Ateş ve akut faz yanıtını baskılamaktadır. Bu nedenle hastaların takibinde akut faz reaktanları değil hasta kliniği daha önemli hale gelmektedir. İlaç kullanımı öncesi hastanın hemogram, biyokimya, lipid profili ve hepatit serolojisi bakılmalıdır. Latent tüberküloz taraması ve bağırsak mukoza yenilenmesinde IL-6' nın görev alması nedeniyle diverkülit ve divertikülozis sorgusu daha çok romatoloji pratiğinde uzun dönem kullanım için önem kazanmaktadır. İlaca bağlı en sık görülen yan etki ise infeksiyonlardır. Karaciğer enzim yüksekliği, lipid profil bozuklukları, sitopeniler (nötropeni, trombositopeni) ve nadir olarak barsak perforasyonu görülebilmektedir. Tosilizumab IL-6 reseptörünü bloke etmesi nedeniyle ölçülen IL-6 değerleri yüksek saptanmaktadır. Bu yüksek serbest IL-6 düzeyleri reseptör bloke olması nedeniyle etkisizdir (10).

Covid-19 nedenli hiperinflamasyon-sitokin salınım sendromunda tosilizumab kullanımı CAR-T (chimeric antigen receptor) hücre sitokin salınım sendromunda kullanımı ile ilişkilidir. CAR-T hücreleri, genetik olarak tasarlanmış yapay $\mathrm{T}$ hücresi reseptörleridir. Tümör hücrelerini genellikle hematojen maligniteler (lenfoma) yok etmek için kullanılmaktadır. Bu tedavi döneminde sitokin salınım sendromu prevalansı \% 58-93 (yaklaşık\% 77) olarak görülmektedir ve sitokin salınım sendromu varlığı, CAR-T hücresi tedavisinin etkinliği ile yakından ilgilidir. Tedavi etkinliğini azaltmadan sitokin salınım sendromunu tosilizumab kullanılarak durdurulması Covid-19 hiperinflamasyonunda kullanılabileceğini düşündürmüştür (11).

Xiaoling Xu ve ark. Mayıs 2020 tarihinde yayınladığı 17 ağır, 4 kritik durumda toplam 21 hastanın dahil edildiği Çin kökenli çalışmada tosilizumab tedavisinin Covid-19 nedenli MAS tedavisinde mortaliteyi azaltan etkili bir tedavi seçeneği olduğu vurgulanmaktadır (12). Bu çalışmada hasta sayısının belirgin az olması nedeniyle tedavi etkinliğini değerlendirmek için yetersiz olduğu kanaati hakimdir. Meta-analizlere bakılacak olursa; 7 retrospektif çalışma ve 592 hastanın dahil edildiği 240 hastanın tosilizumab kullandığı meta-analizde tüm nedenlerle ölüm oranı tosilizumab ile $\% 16,3$, kontrol grubunda \%24, yoğun bakım ve mekanik ventilasyon oranları ise benzer olarak saptanmış. Tosilizumab kullanımının, COVID-19 vakaları için önerilmesi, randomize kontrollü çalışmalardan 
yüksek kaliteli kanıtlar elde edilene kadar durdurulması gerektiği belirtilmiştir (13). Diğer bir meta-analizde ise mortalite oranlarını azalttığı fakat hastanede kalma ve hastalık şiddetine etkisi olmadı saptanmıştır (14). Literatürdeki meta-analizler Covid-19 bağlı MAS tedavisinde tosilizumab kullanımı ile ilgili olumlu ve olumsuz veriler içermektedir. Bu veriler ıșığında ferritin yüksekliği, lenfopeni, yüksek seyreden CRP düzeyleri ve düşük prokalsitonin düzeyi olan hasta gruplarında tosilizumab kullanımının daha etkin olduğunu söyleyebiliriz $(15,16,17,18,19)$. Stone ve ark yaptığı randomize, çift kör plasebo kontrollü çalışmaya 161' i tosilizumab kullanılan toplam 243 hasta dahil edilmiş ve tosilizumab kullanımının, Covid-19 ile hastanede yatan orta derecede hastalığı olan kişilerde entübasyon veya ölümü önlemede etkili olmadığı sonucuna varılmıştır (20). Fakat bu yazıya Leaf ve ark, kendi 3924 hastalık çalışmalarını referans göstererek kritik derecede hasta popülasyonu yansıtmadığını belirterek eleştiride bulunmuştur $(21,22)$. 249 tosilizumab kullanılan hastayı içeren EMPACTA çalışmasının sonuçlarında ise mekanik ventilasyon almayan, hastanede yatan Covid-19 pnömonisi olan hastalarda tosilizumab, mekanik ventilasyon veya ölüme ilerleme olasııı̆ını azalttığı, ancak sağ kalımı iyileştirmediği saptandı (23).

\section{IL-1 Reseptör Antagonisti (Anakinra)}

Anakinra, rekombinant IL-1 reseptör antagonistidir. $100 \mathrm{mg}$ hazır enjektör şeklinde piyasada bulunmaktadır. Romatoloji pratiğinde tedavi dirençli ve komplike ailesel akdeniz ateşi, periyodik ateş sendromları, juvenil idiopatik artrit, erişkin still hastalığı, tedaviye dirençli gut ve idiopatik perikardit tedavisinde kullanılmaktadır. Genellikle 100 mg/gün dozunda subkutan olarak kullanılır. Fakat intiyaç halinde $2-10 \mathrm{mg} / \mathrm{kg}$ dozunda subkutan veya intravenöz olarak kullanılabilir.4-6 saat gibi kısa bir yarılanma ömrü vardır. Kan beyin bariyerini geçebilir. Özellikle sinir sistemi tutulumu olan hastalıklarda bu durum bir avantajdır. Akut faz yanıtını bozmadığı için hastalığın takibinde CRP kullanılabilir. Illacın güvenlik profili diğer biyolojiklere kıyasla daha iyidir. En sık karşılaşılan yan etki lokal cilt reaksiyonudur (24). Makrofaj aktivasyon sendromu tedavisinde kullanımına yönelik olumlu vaka bildirimleri ve çalışmalar mevcuttur. Shakoory ve ark yaptığı faz 3 çalışmada 763 hastalık MAS bulguları olan sepsis hastalarında IL-1 reseptör blokeri kullanımının etkinliğinin olmadığı gösterilmiştir. Fakat alt grup analizlerinde hepatobiliyer disfonksiyon ve dissemine intravasküler koagulasyon olan hastalarda belirgin mortaliteyi azalttığı saptanmıştır (25). Anakinra tedavisi ile özellikle romatolojik hasta grubunda ortaya çıkan MAS bulgularının düzelmesi bu tedavinin Covid-19 nedenli hiperinflamasyon/MAS' ta kullanıla- bileceğini düşündürmüştür. Huet ve ark çalışmasında şiddetli bulguları olan Covid-19 hastalarında anakinra kullanımının hastaların ölüm ve mekanik ventilasyon intiyacını belirgin azalttığını gösterilmiştir (26). Başka bir covid-19' a bağlı hiperinflamasyon ve akut respiratuvar distres sendromu olan hastalarda yüksek doz anakinra kullanımı çalışmasında sağ kalma ve mekanik ventilasyonsuz sağkalımı uzattığı gösterilmiştir (27). Bu çalışmaların tersine anakinra kullanımının Covid-19 nedenli hafif-orta şiddetli pnömoni hastalarında non-invaziv veya mekanik ventilasyon ihtiyacını veya ölümü azaltmada etkili olmadığını gösterilen çaIışmalar mevcuttur (28).

\section{Sonuç}

Anti-sitokin tedavilerden yararlanabilecek hasta grubunun doğru ve vaktinde tanımlanması, etkili ve güvenli bir tedavi planlanması açısından önem taşımaktadır. Doğru hasta grubunu yani covid-19 sitokin fırtınası gelişecek hasta grubunu tahmin etmeye yönelik kriter setleri hazırlanmıştır. Günlük pratik ile uyumlu ve kullanışlı olanlarında ateşin $38^{\circ} \mathrm{C}$ üzerinde seyretmesi, hiperferritinemi, sitopenilerin görülmesi, D-dimer yüksekliği, hepatik hasar göstergelerinin yükselmesi ve sitokin düzey yüksekliği kriterleri mevcuttur $(29,30)$. Fakat T.C Sağlık Bakanlığı önerilerinde de bulunan kesitsel verilerin değil ardışık ölçümlerin dikkate alınması (saatler-günler içerisinde) ve bu durumun birçok bilim dalının (Enfeksiyon hastalıkları-Göğüs hastalıkları-iç Hastalıkları vs) içerisinde olduğu dinamik bir süreç olduğu unutulmamalıdır. Alveol hasarı ilerlemeden anti-sitokin tedavilerinin verilmesi gerektiği ve sitokin fırtınası bulguları oturduktan sonra bu durumu kontrol altına almanın güç olduğu akılda bulundurulmalıdır.

\section{Kaynaklar}

1. Lai C.-C, Shih T.-P, Ko W.-C, Tang H.-J, Hsueh P.-R. Severe acute respiratory syndrome coronavirus 2 (SARS-CoV-2) and coronavirus disease-2019 (COVID-19): The epidemic and the challenges. Int J Antimicrob Agents 2020;55(3):105924.

2. Huang C, Wang Y, Li X, Ren L, Zhao J, Hu Y, et al. Clinical features of patients infected with 2019 novel coronavirus in Wuhan, China. Lancet (London England) 2020;395(10223):497-506.

3. Siddiqi H.K, Mehra M.R. COVID-19 illness in native and immunosuppressed states: a clinical-therapeutic staging proposal. J. Heart Lung Transplant. 2020;39(5):405-7.

4. Fei Zhou, Ting Yu, Ronghui Du, Guohui Fan, Ying Liu, Zhibo Liu, et al. Clinical course and risk factors for mortality of adult inpatients with COVID-19 in Wuhan, China: a retrospective cohort study. Lancet 2020;395(10229):1054-62.

5. Ouédraogo DD, Tiendrébéogo WJS, Kaboré F, Ntsiba H. COVID-19, chronic inflammatory rheumatic disease and anti-rheumatic treatments. Clin Rheumatol. 2020;39(7):2069-75.

6. Soy M, Keser $\mathrm{G}$, Atagündüz $\mathrm{P}$, Tabak $\mathrm{F}$, Atagündüz I, Kayhan S. Cytokine storm in COVID-19: pathogenesis and overview of anti-inflammatory agents used in treatment. Clin Rheumatol. 
2020;39(7):2085-94.

7. Bilimsel Danışma Kurulu Çalışması T.C. Sağlık Bakanlığı, COVID-19 (SARS-CoV-2 enfeksiyonu) Anti sitokin- Antiinflamatuar tedaviler, koagulopati yönetimi. 7 Kasım 2020.

8. Okuda Y. Review of tocilizumab in the treatment of rheumatoid arthritis. Biologics 2008; 2:75.

9. Scott L. Tocilizumab: A Review in Rheumatoid Arthritis. Drugs 2017;77:1865-79.

10. Sheppard M, Laskou F, Stapleton PP, Hadavi S, Dasgupta B. Tocilizumab (Actemra). Hum Vaccin Immunother 2017;13(9):1972-88.

11. Maus M, Levine B. Chimeric Antigen Receptor T-Cell Therapy for the Community Oncologist. Oncologist 2016;21(5):608-17.

12. Xu X, Han M, Li T, Sun W, Wang D, Fu B, et al. Effective treatment of severe COVID-19 patients with tocilizumab. Proc Natl Acad Sci U S A. 2020;117(20):10970-5.

13. Lan SH, Lai CC, Huang HT, Chang SP, Lu LC, Hsueh PR. Tocilizumab for severe COVID-19: a systematic review and meta-analysis. Int J Antimicrob Agents 2020;56(3):106103.

14. Hariyanto TI, Hardyson W, Kurniawan A. Efficacy and Safety of Tocilizumab for Coronavirus Disease 2019 (Covid-19) Patients: A Systematic Review and Meta-analysis. Drug Res (Stuttg). 2021 Jan 5. doi: 10.1055/a-1336-2371.

15. Tleyjeh IM, Kashour Z, Damlaj M, Riaz M, Tlayjeh H, Altannir $\mathrm{M}$, et al. Efficacy and safety of tocilizumab in COVID-19 patients: a living systematic review and meta-analysis. Clin Microbiol Infect. 2021;27(2):215-27.

16. Boregowda U, Perisetti A, Nanjappa A, Gajendran M, Sridharan G, Goyal H. Addition of Tocilizumab to the Standard of Care Reduces Mortality in Severe COVID-19: A Systematic Review and Meta-Analysis. Front Med (Lausanne) 2020;7:586221.

17. Zhao J, Cui W, Tian BP. Efficacy of tocilizumab treatment in severely ill COVID-19 patients. Crit Care 2020;24(1):524.

18. Kotak S, Khatri M, Malik M, Malik M, Hassan W, Amjad A, et al. Use of Tocilizumab in COVID-19: A Systematic Review and Meta-Analysis of Current Evidence. Cureus. 2020;12(10):e10869.

19. Mojtabavi H, Saghazadeh A, Rezaei N. Interleukin-6 and severe COVID-19: a systematic review and meta-analysis. Eur Cytokine Netw 2020;31(2):44-9.

20. Stone JH, Frigault MJ, Serling-Boyd NJ, Fernandes AD, Harvey L, Foulkes AS, et al. Efficacy of Tocilizumab in Patients Hospitalized with Covid-19. N Engl J Med. 2020;383(24):2333-44.

21. Leaf DE, Gupta S, Wang W. Tocilizumab in Covid-19. N Engl J Med. 2021;384(1):86-7.

22. Gupta S, Wang W, Hayek SS, Chan L, Mathews KS, Melamed ML, et al. Association Between Early Treatment With Tocilizumab and Mortality Among Critically III Patients With COVID-19. JAMA Intern Med. 2021;181(1):41-51.

23. Salama C, Han J, Yau L, Reiss WG, Kramer B, Neidhart JD, et al. Tocilizumab in Patients Hospitalized with Covid-19 Pneumonia. N Engl J Med. 2021;384(1):20-30.

24. Anakinra. US Food and Drug Administration (FDA) approved product information. Revised December 2012. US FDA.

25. Shakoory B, Carcillo JA, Chatham WW, Amdur RL, Zhao H, Dinarello CA, et al. Interleukin-1 Receptor Blockade Is Associated With Reduced Mortality in Sepsis Patients With Features of Macrophage Activation Syndrome: Reanalysis of a Prior Phase III Trial. Crit Care Med. 2016;44(2):275-81.

26. Huet T, Beaussier H, Voisin O, Jouveshomme S, Dauriat G, Lazareth I, et al. Anakinra for severe forms of COVID-19: a cohort study. Lancet Rheumatol. 2020;2(7):393-400.

27. Cavalli G, De Luca G, Campochiaro C, Della-Torre E, Ripa M, Canetti $\mathrm{D}$, et al. Interleukin-1 blockade with high-dose anakinra in patients with COVID-19, acute respiratory distress syndrome, and hyperinflammation: a retrospective cohort study. Lancet Rheumatol. 2020;2(6):325-31.

28. CORIMUNO-19 Collaborative group. Effect of anakinra versus usual care in adults in hospital with COVID-19 and mild-to-moderate pneumonia (CORIMUNO-ANA-1): a randomised cont- rolled trial. Lancet Respir Med. 2021;9(3):295-304.

29. Webb BJ, Peltan ID, Jensen P, Hoda D, Hunter B, Silver A, et al. Clinical criteria for COVID-19-associated hyperinflammatory syndrome: a cohort study. Lancet Rheumatol. 2020;2(12):754-63.

30. Caricchio R, Gallucci M, Dass C, Zhang X, Gallucci S, Fleece $\mathrm{D}$, et al. Preliminary predictive criteria for COVID-19 cytokine storm. Ann Rheum Dis. 2021;80(1):88-95. 